\title{
The Relationship between Type 2 Diabetes and Total Ghrelin Level in a Population Sample in the United Arab Emirates
}

\author{
Alaa Farajallah ${ }^{1}$, AbdElazim Ahmed ${ }^{2}$, Nihal Abdullah ${ }^{3}$, Salah Abusnana ${ }^{4}$, \\ Prem Andrew ${ }^{5}$ \\ ${ }^{1}$ Lecturer, Clinical Pharmacy and Pharmacy Practice Department, Pharmacy College, Ajman University of \\ Science and Technology, Ajman, United Arab Emirates. \\ ${ }^{2}$ Professor, Dean of Pharmacy College, Pharmacy College, Ajman University of Science and Technology, \\ Ajman, United Arab Emirates. \\ 3 Assistant Professor, Pharmacy College, Ajman University of Science and Technology, Ajman, United Arab \\ Emirates. \\ ${ }^{4}$ Chief Medical Officer at Rashid Centre for Diabetes and Research (RCDR), Ajman, United Arab Emirates. \\ ${ }^{5}$ Laboratory Technologist at RCDR, Ajman, United Arab Emirates.
}

\begin{abstract}
There is a debate about the relation between ghrelin and insulin. Many researchers have found low ghrelin level in diabetic patients while others claim that no correlation between them. Thus further investigations are needed to clarify the precise role of ghrelin in the development and/ or treatment of diabetes.

To date and up to our knowledge, this is the first study to be conducted on Emirati people in the United Arab Emirates (UAE) to explore the relationship between ghrelin concentration and type 2 diabetes. This research aimed for better understanding about the role of ghrelin hormone in the pathogenesis process of diabetes disease, in an attempt to help patients who find it difficult to control their diabetes by studying the relation between serum total ghrelin levels; insulin and insulin resistance in patients with type 2 diabetes mellitus in the UAE and relate them to the glycemic condition. A cross sectional study was conducted at Rashid Centre for Diabetes and Research (RCDR) in Ajman, UAE. Thirty patients were selected from the outpatient clinic at RCDR and fifteen healthy controls were included in this study.

The Blood sample was collected from each participant and analyzed for HbAlc, insulin, glucose and total ghrelin level. Ghrelin level was measured using the enzyme-linked immunosorbent assay (ELISA) technique. The results of this study showed that mean ghrelin level was low in both insulin-resistant and noninsulin resistant diabetic patients as compared to the control group. In conclusion, low ghrelin level is associated with poor diabetes control and bad prognosis parameters in type 2 diabetic patients.
\end{abstract}

KEYWORDS -Ghrelin, Diabetes, Insulin resistance, United Arab Emirates (UAE).

\section{INTRODUCTION}

Diabetes is currently the fastest growing debilitating disease in the world [1]. Being a chronic disease, diabetes needs to be controlled and managed early to avoid its complications and sequelae. Ghrelin is a peptide hormone with anabolic functions [2]. It stimulates growth hormone secretion and appetite, decreases fat utilization as a metabolic fuel and increases fat storage in the adipose tissue [3]. Moreover, ghrelin exerts variable effects on glucose metabolism, heart function and inflammatory processes [4]. Due to these characteristics ghrelin has become a hot topic for research focusing on diabetes and its co-morbidities such as hypertension, obesity and atherosclerosis.

The majority of the publications addressing the relationship between ghrelin and insulin resistance and/or diabetic states suggest that a correlation between ghrelin and insulin resistance and/or diabetes might exist [5-7]. A recent study showed that a high circulating ghrelin level was associated with insulin resistance [8]. Furthermore, in obese diabetics, the fasting serum ghrelin is also low compared to the non-obese diabetics $[9,10]$. This decrease may play a causative role in the development of type 2 diabetes mellitus [3].

There is a significant correlation between the plasma level of ghrelin and serum level of insulin [6]. Most available data suggest a negative association between systemic ghrelin and insulin levels. On the other hand, contradictory results i.e. no association between ghrelin and pathologies of glucose metabolism have been published. In healthy middle-aged men in a euglycaemic hyperinsulinemic clamp study, no association between insulin sensitivity and ghrelin concentration was observed [11]. In addition, ghrelin concentration of subjects with type 2 diabetes was not different from those of normal weight controls and ghrelin concentration seemed to vary according to the body mass index (BMI) and not by diabetic status. Obese subjects with type2 diabetes had 
lower and lean subjects with type2 diabetes had higher ghrelin concentrations indicating that ghrelin did not appear to be associated with glucose or insulin metabolism [12].

It can be concluded that the independent role of body BMI, glucose and insulin in ghrelin regulation is still controversial.

\section{STUDY OBJECTIVES:}

To determine if there is possible relationship between fasting total plasma ghrelin level and type 2 diabetes in Emirati population in the UAE and to compare between the fasting total ghrelin level in type 2 diabetic patients and normal healthy subjects.

\section{Subjects}

\section{METHODOLOGY}

A) Patients: After ethical committee approval, thirty adult Emirati patients with type 2 diabetes aged between 40-60 years with normal liver and kidney functions of BMI $<30 \mathrm{~kg} / \mathrm{m}^{2}$ were enrolled during the month of September 2013 at RCDR in Ajman, UAE. Patients' records were screened to identify their eligibility as type 2 diabetic participants. Type 2 diabetes was defined according to the WHO 1999 criteria for diabetes, i.e., (blood glucose levels must have been taken within the last 12 months and must have still been within the range for diagnosis of that disease). Subjects were approached and informed about the study and provided with a medical participant's information sheet when they attended their out-patient appointment at the diabetic clinic in the RCDR. At this stage, appointments were arranged for the participants willing to participate in the study and all the enrolled patients were fasted overnight.

\section{Exclusion Criteria}

Exclusion criteria for patient's group:

1- Non-Emirati patients

2- Age less than 40 and more than 60 years old.

3- Patients with previous diagnosis and evidence of liver failure or disease, renal failure (plasma creatinine above $1.5 \mathrm{mg} / \mathrm{dL}$ ), cancer, chronic autoimmune, thyroid disease, history of alcohol, drug abuse and smoking. 4-Patients with any obvious major complications of diabetes, including heart diseases and patients who were taking lipid lowering medications.

B) Controls: Control participants were recruited during educational campaigns organized by RCDR at certain governmental institutions and fifteen apparently healthy participants were recruited. Their age and weight ranges were comparable to that of the enrolled patients. Participants with previous diagnosis and evidence of liver failure or disease, renal failure (plasma creatinine above $1.5 \mathrm{mg} / \mathrm{dL}$ ), cancer, chronic autoimmune, thyroid disease, history of alcohol, drug abuse and smoking were excluded.

\section{Laboratory measurements}

$7 \mathrm{~mL}$ of blood samples were collected from each participant after a 10-12 hour overnight fasting. Sample analysis was performed at the laboratory of RCDR in Ajman, UAE. One milliliter of fresh blood was added to EDTA tube to measure the glycated hemoglobin and the rest of blood was left at room temperature for 30 minutes for clotting. The clotted samples were centrifuged at $3000 \mathrm{rpm}$ for 15 minutes at $4 \pm 2^{\circ} \mathrm{C}$. Serum samples were then separated and acidified with $\mathrm{HCl}$ and stored at $-20 \pm 5^{\circ} \mathrm{C}$ till analysis.

All samples were analyzed for the following:

Fasting blood glucose was analyzed by Roche/Hitachi Cobas 6000 (c-501) analyzer using enzymatic glucose assay with hexokinase.

The HbA1c determination was based on the turbidimetric inhibition immunoassay (TINIA) for hemolysed whole blood using Roche/ Hitachi Cobas 6000 (c-501) machine.

Serum insulin was measured using Electrochemiluminescence (ECL) immunoassay using Roche/Hitachi Cobas 6000 (e-601) analyzer.

The fasting total ghrelin level was analyzed by Enzyme Linked Immunosorbent Assay (ELISA) technique using Demeditec Diagnostics GmbH kit, Germany. 
Insulin resistance parameters were calculated from fasting glucose and insulin levels, using Homeostasis Model of Assessment (HOMA) calculator software, downloaded freely from;

[http://www.dtu.ox.ac.uk/homacalculator/download.php].

Body Mass Index values were calculated according to the following equation: BMI= Weight $(\mathrm{Kg}) / \mathrm{Height}(\mathrm{m} 2)$.

DATA ANALYSIS: The results were expressed as (Mean \pm Standard Deviation), because they were normally distributed according to Kolmogorov-Smirnov test. Two tailed pooled t-test was used for the comparison of means of the measured parameters between the two groups. Correlation coefficients between serum ghrelin levels and other parameters were calculated.

Data entry and analysis were conducted using the Statistical Package for the Social Science (SPSS) software version 21. The P-values and confidence intervals were calculated and P-value less than 0.05 was considered statistically significant, with confidence interval (CI) of $95 \%$.

\section{Ethical Considerations}

The study protocol was approved by the Al Qassimi Clinical Research Centre (AQCRC), the first Clinical Research Centre at the Ministry of Health in the UAE on 01/May/2013.

\section{RESULTS}

The results of the biochemical parameters in study patients and control subjects were presented in Table 1. The mean ghrelin level in patients $(n=30)$ and control group $(n=15)$ were $325.10 \pm 150.365 \mathrm{pg} / \mathrm{ml}$ and $350.93 \pm 141.982 \mathrm{pg} / \mathrm{ml}$ respectively. The patient's group was subdivided into insulin resistant group (HOMAIR $\geq 3)(\mathrm{n}=8)$ with a ghrelin level mean $283 \pm 171 \mathrm{pg} / \mathrm{ml}$ and non-insulin resistant (non-IR) (HOMA < 3) $(\mathrm{n}=22)$ with a ghrelin level mean $340 \pm 143$. This was done because when the insulin levels of each patient were studied individually, the hyperinsulinemic patients had very high insulin levels that affected the overall mean of insulin level of the diabetic patients group. Therefore, this subdivision was performed (table 2).

Different biochemical parameters of patients with type 2 diabetes and control groups.

Serum total ghrelin concentrations were significantly lower $(p<0.0001)$ in IR group $(n=8)$ as well as non-IR group $(n=22)(p<0.001)$ than the control group as shown in Figure 1.

The HbA1c results were significantly higher in non-IR group $(\mathrm{p}<0.0001)$ than the control group, indicating a poor control on the blood glucose 2-3 months prior to the investigation.

Table 1: Serum biochemical parameters of patients with type 2 diabetes and the control groups (Mean \pm Standard deviation)

\begin{tabular}{|c|c|c|}
\hline & $(\mathbf{n}=\mathbf{3 0})$ & Control $(n=15)$ \\
\hline Ghrelin $(\mathrm{pg} / \mathrm{mL})$ & $325.1 \pm 150.365$ & $350.93 \pm 141.982$ \\
\hline Fasting Blood Sugar $(\mathrm{mmol} / \mathrm{l})$ & $7.53 \pm 2.345$ & $5.40 \pm 0.507 * *$ \\
\hline $\mathrm{HbAlc}(\%)$ & $7.40 \pm 1.404$ & $5.73 \pm 0.458^{* *}$ \\
\hline Insulin $(\mu \mathrm{IU} / \mathrm{mL})$ & $20.52 \pm 19.17$ & $23.47 \pm 23.658$ \\
\hline BMI & $27.614 \pm 2.141$ & $27.245 \pm 2.221$ \\
\hline HOMA 2- IR & $2.52 \pm 1.326$ & $2.29 \pm 1.437$ \\
\hline HOMA $2-\% S$ & $90.9 \pm 56$ & $142.4 \pm 56.3$ \\
\hline HOMA 2- \%B & $53.76 \pm 30.37$ & $60.74 \pm 35.06$ \\
\hline
\end{tabular}

$* * \mathrm{p}<0.0001$ 
The Relationship between Type 2 Diabetes and Total Ghrelin Level in a Population Sample in ...

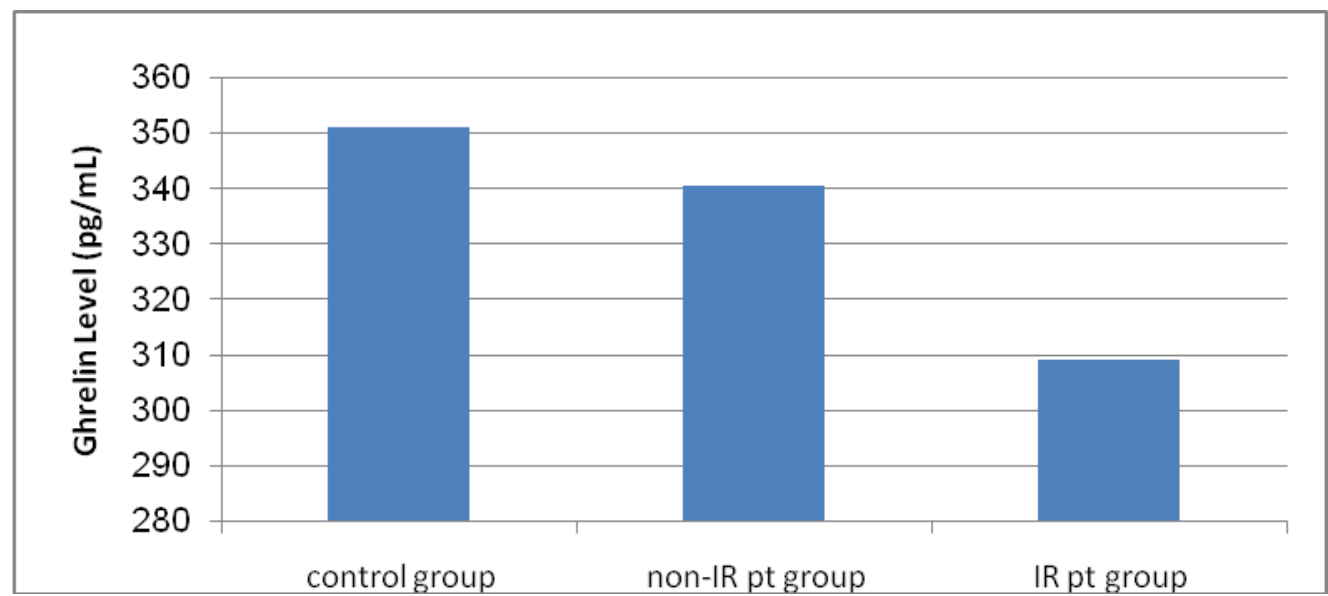

Figure 1: Comparison between ghrelin level in the control, non-IR and IR groups.

Non-IR: non-insulin resistance

IR: insulin resistance

Table 2: Serum ghrelin, BMI, insulin resistance parameters and HbA1c in the IR and non-IR patients and the control groups (mean \pm standard deviation)

Diabetic Patients $(\mathbf{n}=30)$

\begin{tabular}{|c|c|c|c|c|}
\hline & IR $(n=8)$ & Non-IR $(n=22)$ & Control $(n=30)$ & Significance \\
\hline Ghrelin (pg/ml) & $308.9 \pm 177.8$ & $340.4 \pm 143.2$ & $350.93 \pm 141.982$ & $\mathrm{~b}, \mathrm{c}$ \\
\hline $\begin{array}{l}\text { Fasting Blood Sugar } \\
(\mathrm{mmol} / \mathrm{l})\end{array}$ & $6.812 \pm 1.508$ & $7.804 \pm 2.519$ & $5.40 \pm 0.507$ & $\mathrm{~b}, \mathrm{c}$ \\
\hline $\mathrm{HbA1c}(\%)$ & $7.422 \pm 1.151$ & $7.418 \pm 1.366$ & $5.73 \pm 0.458$ & $\mathrm{~b}, \mathrm{c}$ \\
\hline Insulin $(\mu \mathrm{IU} / \mathrm{ml})$ & $41.4 \pm 28.06$ & $12.929 \pm 4.348$ & $23.47 \pm 23.658$ & $\mathrm{a}$ \\
\hline BMI & $27.84 \pm 2.17$ & $27.53 \pm 2.17$ & $27.245 \pm 2.221$ & \\
\hline HOMA 2- IR & $4 \pm 1.485$ & $1.85 \pm 0.638$ & $2.29 \pm 1.437$ & $a, b$ \\
\hline HOMA 2- \%S & $28.15 \pm 10.5$ & $62.91 \pm 29.25$ & $142.4 \pm 56.3$ & $a, b$ \\
\hline HOMA 2-\% B & $148.1 \pm 61.8$ & $71.28 \pm 35.84$ & $60.74 \pm 35.06$ & $a, b$ \\
\hline
\end{tabular}

(a): Significant difference $(\mathrm{p}<0.05)$ between IR Diabetic and Non-IR groups.

(b): Significant difference $(\mathrm{p}<0.05)$ between IR Diabetic and Control groups.

(c): Significant difference $(\mathrm{p}<0.05)$ between Non-IR Diabetic and Control groups.

HOMA2-IR : Homeostasis model assessment insulin resistance index

HOMA2-\%S: Homeostasis model assessment insulin sensitivity

HOMA2-\%B: Homeostasis model assessment beta cell function

Correlation between ghrelin level and other measured parameters in the three studied groups

Figures (2-5) show the correlation coefficient and $P$-values for the correlation between ghrelin level and the measured parameters in the study groups. A negative correlation is shown in (Figures 2,3) between total ghrelin level, FBS and HbA1c in non-IR group $(P \leq 0.05)$. In IR group, a positive correlation was found between total ghrelin levels and insulin $(P$ $\leq 0.05$ ) (Figure 4). Ghrelin level correlated positively with insulin sensitivity in all groups. Moreover, it correlated positively with beta cell function only in non-IR group $(P \leq 0.05)$. Furthermore, our results illustrate that ghrelin level was not correlated with insulin resistance (Figure 5). 


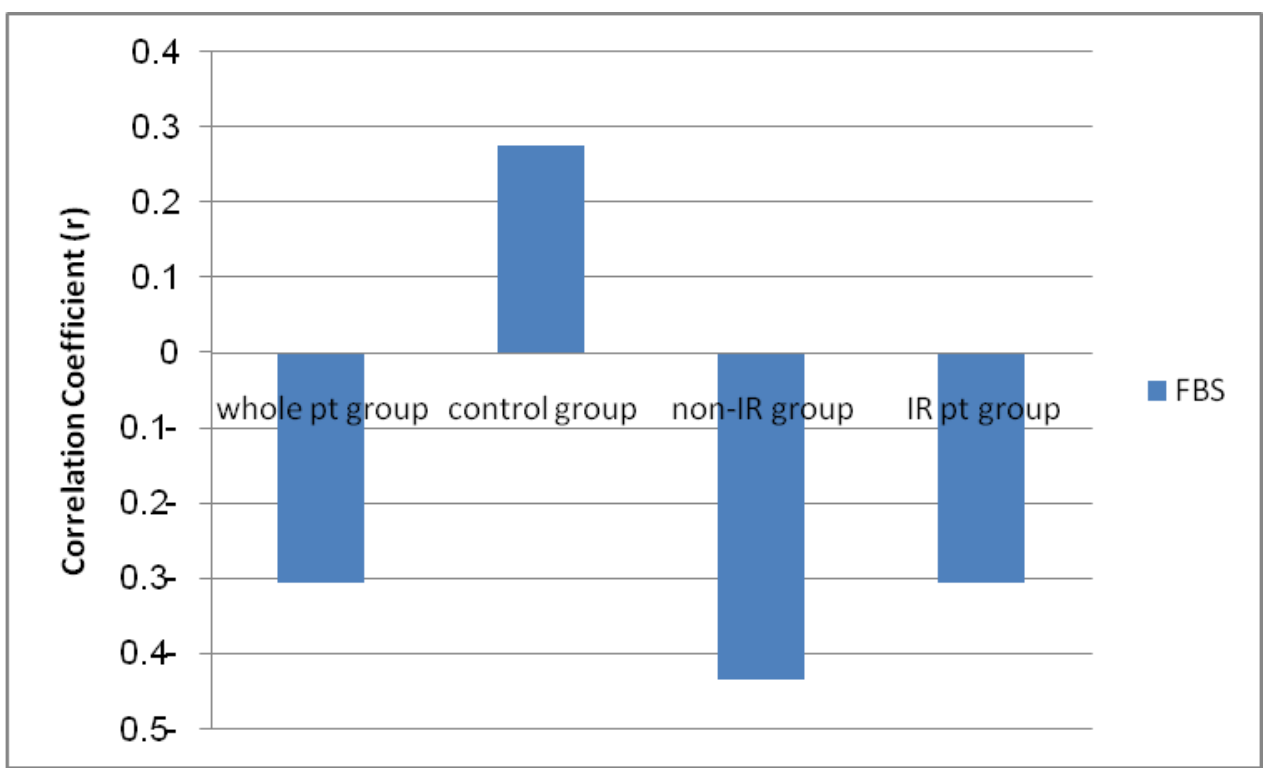

Figure 2: The relationship between ghrelin and fasting blood sugar in the three studied groups

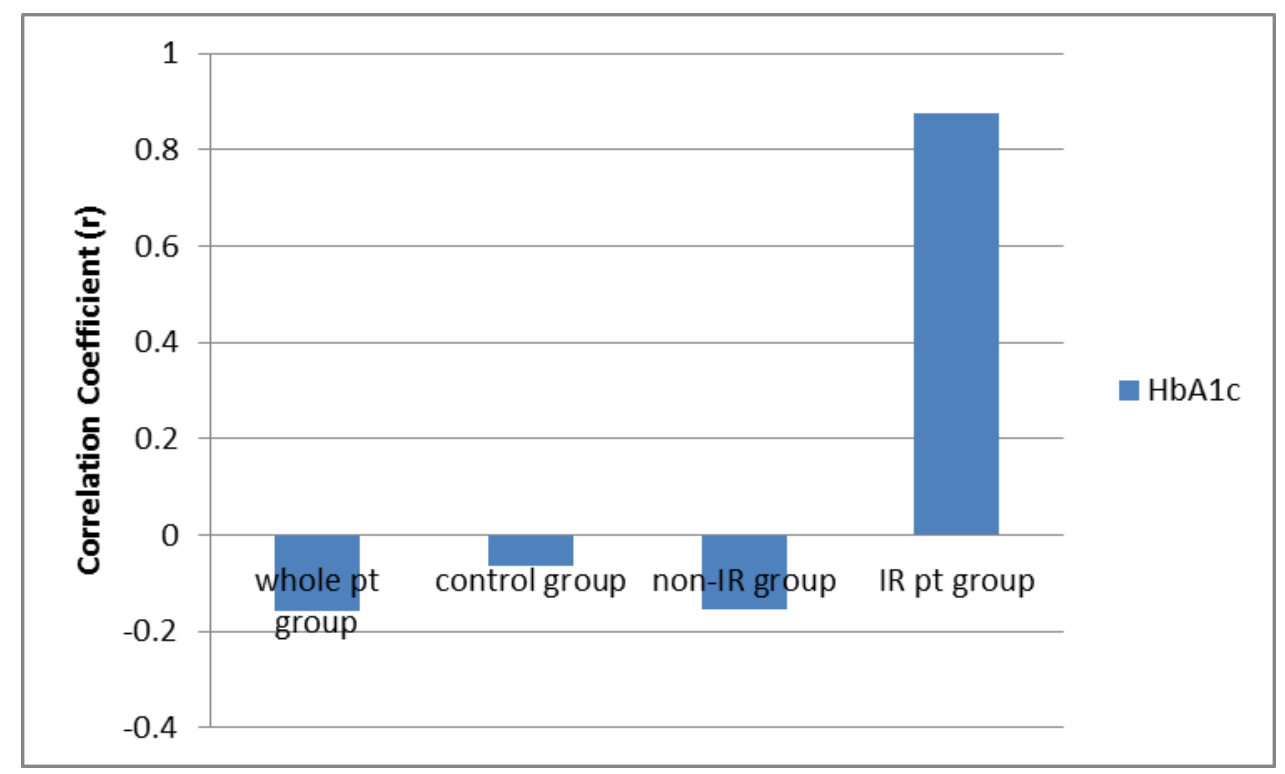

Figure 3: The relationship between ghrelin and $\mathrm{HbA1c}$ in the three studied groups 


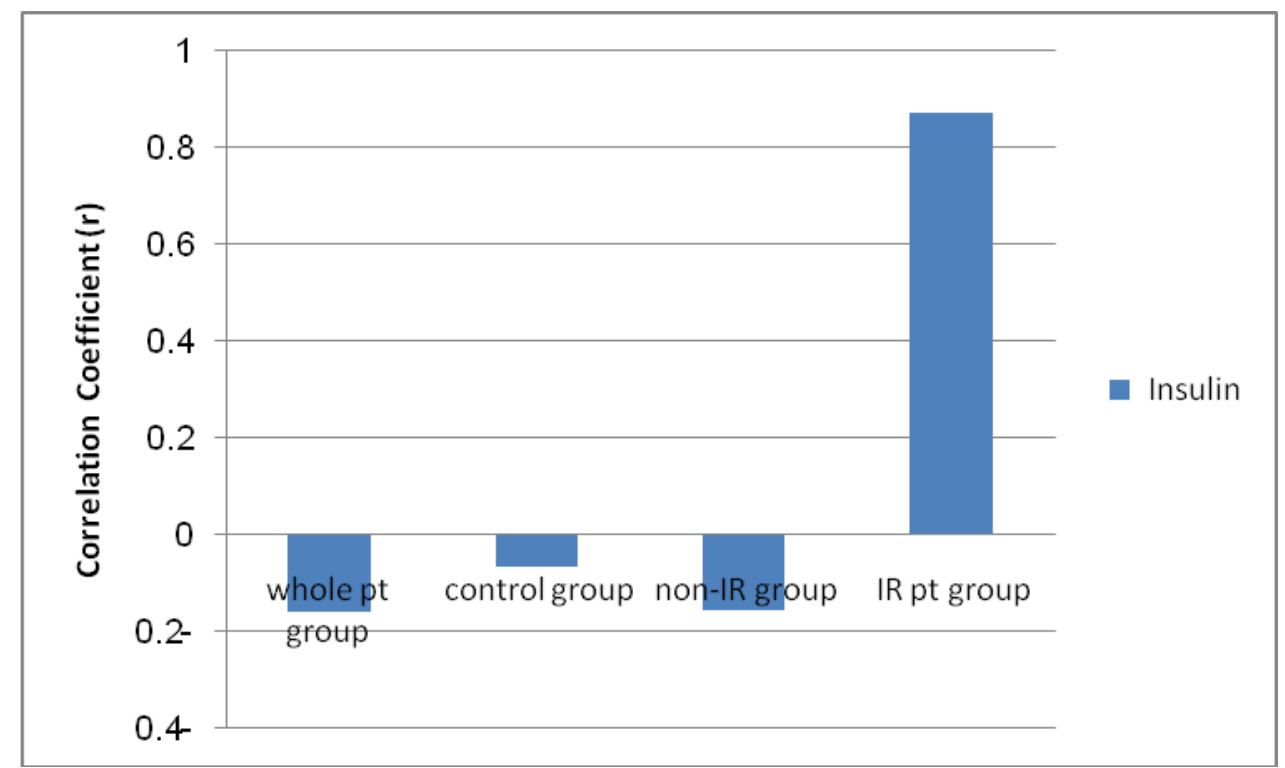

Figure 4: The relationship between ghrelin and insulin in the three studied groups

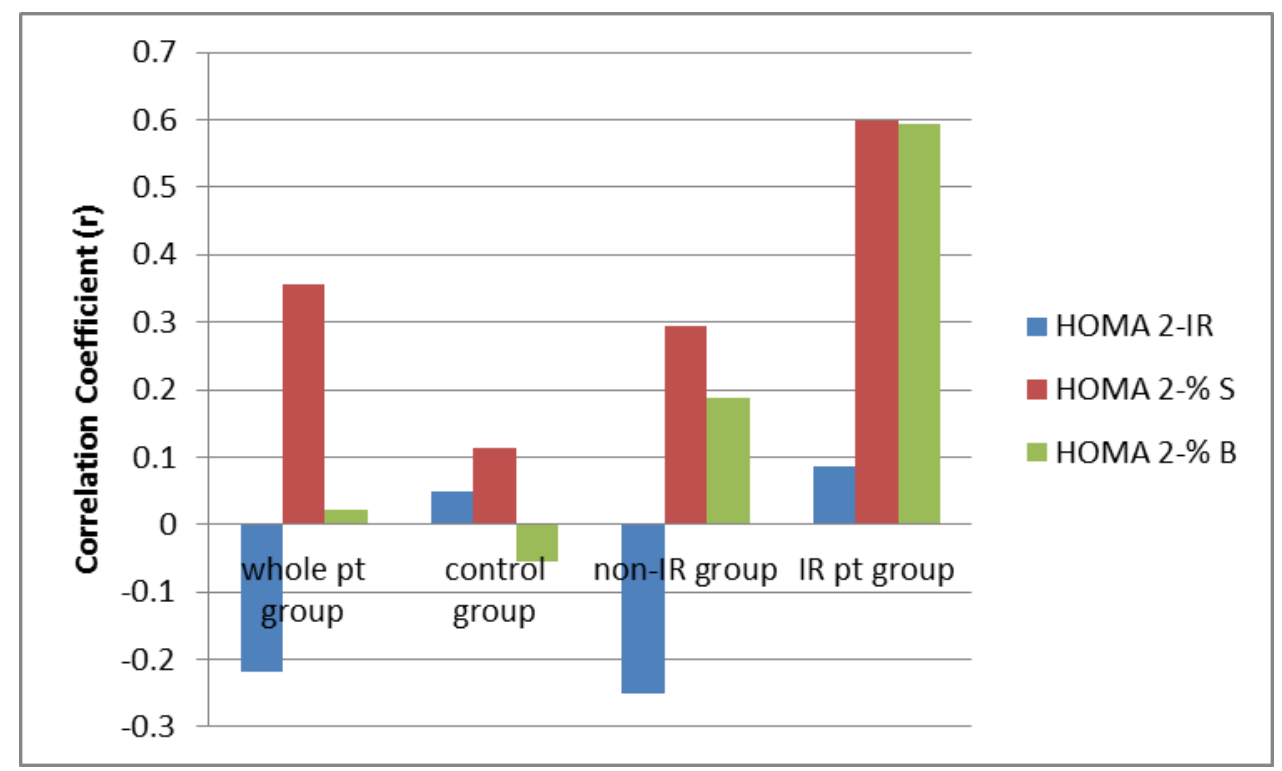

Figure 5: The relationship between ghrelin and HOMA parameters in the three studied groups

\section{Study populations and design}

\section{DISCUSSION}

In the current study, subjects were recruited between the ages of 40 and 60 years. This age group was selected in accordance with the nature of the disease state, because type 2 diabetes was commonly known as late-onset diabetes [13]. Furthermore, the statistics have shown that most of the patients with type 2 diabetes in the UAE fall within this age group [14].

All participants in both groups were Emirati. The patients' group is a representative sample of type 2 diabetes population. To our knowledge, this is the first study exploring the relationship between total ghrelin hormone and type 2 diabetes in the UAE.

\section{Ghrelin concentrations in the studied groups}

The total ghrelin was chosen to be measured, because it is previously shown to be associated with type 2 diabetes in a cross-sectional study [3]. 
We found that ghrelin concentrations of patients with type 2 diabetes was significantly lower $(P<0.05)$ than those of controls group which was in line with previous studies [7, 15-17]. Our findings support the view that low ghrelin level could have a causative role in the development of type 2 diabetes. Furthermore, our results were also confirmed by a previous study which proved that low ghrelin levels are independently associated with insulin resistance and type 2 diabetes [5].

On the other hand, our results were not supported by Shiiya et al., 2002 [12] work who found that ghrelin concentrations of subjects with type 2 diabetes were not different from those of normal weight controls and ghrelin concentrations seemed to vary according to the BMI and not by diabetes. One study revealed that obese subjects with type 2 diabetes had lower ghrelin levels than lean subjects with type 2 diabetes. This indicated that ghrelin did not appear to be associated with glucose or insulin metabolism, thus the independent role of BMI, glucose and insulin in ghrelin regulation is still controversial [12].

\section{Ghrelin level versus insulin level}

Regarding the exact relationship between ghrelin and insulin our results showed that ghrelin level is positively correlated with insulin concentrations in IR diabetic patients $(P<0.005)$. Our result was supported by Date et al., 2002; Lee et al., $2002[18,19]$ who found that ghrelin stimulated insulin secretion.

On the other hand, conflicting results have been reported [20, 21]. Some reports suggested that ghrelin either stimulates $[18,19,22]$ or inhibits insulin secretion depending on the experimental condition [23,24]. There have been also some claims that insulin (and / or glucose) lowers circulating ghrelin [25]. These findings suggest that ghrelin plays both physiological and pathophysiological roles in insulin release that should be further investigated.

On the other hand, our result was not supported by other workers who showed a negative correlation between total ghrelin and the levels of insulin [11,26, 27, 28]. Furthermore, many earlier studies showed that ghrelin has been shown to inhibit insulin release in some experimental situations [24, 29]. However these inconsistencies may reflect species differences and/ or differences in experimental design as different doses, different times of observation and in vitro versus in vivo experiments $[30,31]$.

Other possible reason could be measuring the total ghrelin without measuring its two forms (acylated ghrelin (AG) and unacylated ghrelin (UAG)) separately. These different forms of ghrelin can be regarded as different hormones [32]. For example, AG and UAG might possess different or even opposite biological effects on insulin secretion, appetite or on adipogenesis as reviewed by Soares and Leite-Moreira 2008 [33].

Furthermore, ghrelin administration seems also to increase glucose levels though it is not known whether this is due to a decrease of insulin secretion or it is a direct effect [33]. It seems that AG and UAG might be involved in the energy metabolism by modulating the release of one of its most crucial hormones, insulin and that AG and UAG might have different, even opposite effects, despite the fact that contradictory effects of ghrelin on insulin release on pancreatic cells have also been published [25].

\section{v. CONCLUSION}

Low ghrelin level was associated with poor diabetes control (high HbA1c values), insulin resistance parameters (high HOMA 2 IR and low HOMA-\%S) in patients with diabetes. Therefore it can be concluded that low ghrelin level is an indicator of adverse consequences in patients with diabetes. These findings were consistent with a role for endogenous ghrelin in the regulation of insulin secretion and suggest that ghrelin antagonism may improve $\beta$-cell function.

RECOMMENDATIONS: In view of the above findings and discussions, the following recommendations are made:

1- Similar comparative studies to be conducted in the UAE with a larger sample size in patient with diabetes compared with control groups as this will provide more generalized results.

2- The results of this study can be used as a baseline and it will be useful for comparison with any future related studies.

3- Further studies to be conducted measuring the different forms of ghrelin (AG and UAG), obestatin and GOAT (GhrelinO- acyltransferase).

\section{LIMITATIONS:}

1- Insulin resistance was evaluated by HOMA software and not by the euglycemic hyper-insulinemic clamp technique.

2- This study didn't measure the levels of AG and UAG, thus we were not able to evaluate and compare the two forms of ghrelin and the AG/UAG ratio in our study. In view of the current research, the physiological importance of the AG/UAG ratio, and also obestatin, warrants further studies to measure all peptides of the ghrelin family, as well as GOAT. 


\section{REFERENCES}

[1] Lam, D. W., \&LeRoith, D. The worldwide diabetes epidemic. Current Opinion in Endocrinology, Diabetes and Obesity, 19(2),2012, 93-96.

[2] Kojima, M., \&Kangawa, K. Ghrelin: structure and function. Physiological reviews, 85(2), 2012, 495-522.

[3] Wren, A. M., Small, C. J., Ward, H. L., Murphy, K. G., Dakin, C. L., Taheri, \& Bloom, S. R. The novel hypothalamic peptide ghrelin stimulates food intake and growth hormone secretion. Endocrinology, 141(11), 2000, 4325-4328.

[4] Meier, U., \&Gressner, A. M. Endocrine regulation of energy metabolism: review of pathobiochemical and clinical chemical aspects of leptin, ghrelin, adiponectin, and resistin. Clinical Chemistry, 50(9), 2004, 1511- 1525.

[5] Pöykkö, S. M., Kellokoski, E., Hörkkö, S., Kauma, H., Kesäniemi, Y. A., \&Ukkola, O. Low plasma ghrelin is associated with insulin resistance, hypertension, and the prevalence of type 2 diabetes. Diabetes, 52(10), 2003, 2546-2553.

[6] Katsuki, A., Urakawa, H., Gabazza, E. C., Murashima, S., Nakatani, K., Togashi, K., \& Sumida, Y. Circulating levels of active ghrelin is associated with abdominal adiposity, hyperinsulinemia and insulin resistance in patients with type 2 diabetes mellitus. European Journal of Endocrinology, 151(5), 2004, 573-577.

[7] Ukkola, O. Ghrelin in Type 2 diabetes mellitus and metabolic syndrome. Molecular and cellular endocrinology, 340(1), 2011, 2628.

[8] Amini, P., Wadden, D., Cahill, F., Randell, E., Vasdev, S., Chen, X., \& Sun, G. Serum Acylated Ghrelin Is Negatively Correlated with the Insulin Resistance in the CODING study. PloS one, 7(9), 2012, e45657.

[9] Guang, Y., Shusheng, Z., \&Mengwen, S. Relationship between plasma ghrelin and body fat level in fasting patients. ActaUniversitatisMedicinalis Anhui, 4, 2008, 020.

[10] Al-Hakeim, H. K., \& Ali, M. M. Low ghrelin level is associated with poor control and bad prognosis parameters in obese diabetic patients. Journal of Diabetology, 2012, 1, 5 .

[11] Fagerberg, B., Hultén, L. M., \&Hulthe, J. Plasma ghrelin, body fat, insulin resistance, and smoking in clinically healthy men: the atherosclerosis and insulin resistance study. Metabolism, 52(11), 2003, 1460-1463.

[12] Shiiya, T., Nakazato, M., Mizuta, M., Date, Y., Mondal, M. S., Tanaka, M., \&Matsukura, S. Plasma ghrelin levels in lean and obese humans and the effect of glucose on ghrelin secretion. Journal of Clinical Endocrinology \& Metabolism, 87(1), $2002,240-244$.

[13] Hansen, T. K., Dall, R., Hosoda, H., Kojima, M., Kangawa, K., Christiansen, J. S., \&Jørgensen, J. O. L. Weight loss increases circulating levels of ghrelin in human obesity. Clinical endocrinology, 56(2), 2002, 203-206.

[14] Abraham, R. MENA: The dawn of a new era, 2011, Available at: http://www. middleeasthealthmag.com, [Accessed: 20 September 2013].

[15] Barazzoni, R., Zanetti, M., Ferreira, C., Vinci, P., Pirulli, A., Mucci, M., \&Guarnieri, G. Relationships between desacylated and acylated ghrelin and insulin sensitivity in the metabolic syndrome. Journal of Clinical Endocrinology \& Metabolism, 92(10), 2007, 3935-3940.

[16] Yada, T., Dezaki, K., Sone, H., Koizumi, M., Damdindorj, B., Nakata, M., \&Kakei, M. Ghrelin regulates insulin release and glycemia: physiological role and therapeutic potential. Current Diabetes Reviews, 4(1), 2008, 18-23.

[17] Wadden, D., Cahill, F., Amini, P., Randell, E., Vasdev, S., Yi, Y., \& Sun, G. Serum acylated ghrelin concentrations in respon se to short-term overfeeding in normal weight, overweight, and obese men. PLoS One, 7(9), 2012, e45748.

[18] Date, Y., Nakazato, M., Hashiguchi, S., Dezaki, K., Mondal, M. S., Hosoda, H., \&Matsukura, S. Ghrelin is present in pancreatic $\alpha-$ cells of humans and rats and stimulates insulin secretion. Diabetes, 51(1), 2002, 124-129.

[19] Lee, H. M., Wang, G., Englander, E. W., Kojima, M., \& Greeley Jr, G. H. Ghrelin, a new gastrointestinal endocrine peptide that stimulates insulin secretion: enteric distribution, ontogeny, influence of endocrine and dietary manipulations. Endocrinology, 143(1), 2002, 185-190.

[20] Stylianou, C., Galli-Tsinopoulou, A., Farmakiotis, D., Rousso, I., Karamouzis, M., Koliakos, G., \&Nousia-Arvanitakis, S. Ghrelin and leptin levels in obese adolescents.Relationship with body fat and insulin resistance. HORMONES-ATHENS-, 6(4), $2007,295$.

[21] Cui, C., Ohnuma, H., Daimon, M., Susa, S., Yamaguchi, H., Kameda, W., \& Kato, T. Ghrelin infused into the portal vein inhibit s glucose-stimulated insulin secretion in Wistar rats. Peptides, 29(7), 2008, 1241-1246.

[22] Adeghate, E., \&Ponery, A. S. Ghrelin stimulates insulin secretion from the pancreas of normal and diabetic rats. Journal of neuroendocrinology, 14(7), 2002, 555-560.

[23] Egido, E. M., Rodriguez-Gallardo, J., Silvestre, R. A., \& Marco, J. Inhibitory effect of ghrelin on insulin and pancreatic somatostatin secretion. European Journal of Endocrinology, 146(2), 2002, 241-244.

[24] Reimer, M. K., Pacini, G., \&Ahrén, B. Dose-dependent inhibition by ghrelin of insulin secretion in the mouse.Endocrinology, 144(3), 2003, 916-921.

[25] Salehi, A., Dornonville de la Cour, C., Håkanson, R., \& Lundquist, I. Effects of ghrelin on insulin and glucagon secretion: a study of isolated pancreatic islets and intact mice. Regulatory peptides, 118(3), 2004, 143-150.

[26] Pacifico, L., Poggiogalle, E., Costantino, F., Anania, C., Ferraro, F., Chiarelli, F., \&Chiesa, C.Acylated and nonacylated ghrelin levels and their associations with insulin resistance in obese and normal weight children with metabolic syndrome. European Journal of Endocrinology, 161(6), 2009, 861-870.

[27] Stepien, M., Rosniak-Bak, K., Paradowski, M., Misztal, M., Kujawski, K., Banach, M., \&Rysz, J. Waist circumference, ghrelin and selected adipose tissue-derived adipokines as predictors of insulin resistance in obese patients: preliminary results. Medical science monitor: international medical journal of experimental and clinical research, 17(11), 2001, PR13.

[28] Tong, J., Prigeon, R. L., Davis, H. W., Bidlingmaier, M., Tschöp, M. H., \&D'Alessio, D.Physiologic concentrations of exogenou sly infused ghrelin reduces insulin secretion without affecting insulin sensitivity in healthy humans. Journal of Clinical Endocrinology \& Metabolism, 98(6), 2013, 2536-2543.

[29] Broglio, F., Arvat, E., Benso, A., Gottero, C., Muccioli, G., Papotti, M., \&Ghigo, E. Ghrelin, a natural GH secretagogue produced by the stomach, induces hyperglycemia and reduces insulin secretion in humans. Journal of Clinical Endocrinology \& Metabolism, 86(10), 2001, 5083-5083.

[30] Abdullah et al. Correlation between plasma ghrelin, leptin and insulin levels in non-diabetic and experimentally- induced diabetic and lean conditions. PhD submitted to faculty of medicine, Alexandria University, 2009.

[31] Zhang, K., Wei, H., Zhang, Y., Wang, S., Li, Y., Dai, Y., \& Li, N. Effects of ghrelin on in vitro development of porcine in vitro fertilized and parthenogenetic embryos. Journal of Reproduction and Development, 53(3), 2007, 647.

[32] Vartiainen, J. GHRELIN, OBESITY AND TYPE 2 DIABETES (2009). Available at: http://herkules.oulu.fi/isbn9789514290657/isbn9789514290657.pdf, [Accessed on: 20 September, 2013].

[33] Soares, J. B., \&Leite-Moreira, A. F. Ghrelin, des-acyl ghrelin and obestatin: three pieces of the same puzzle. Peptides, 29(7), 2008, 1255-1270. 